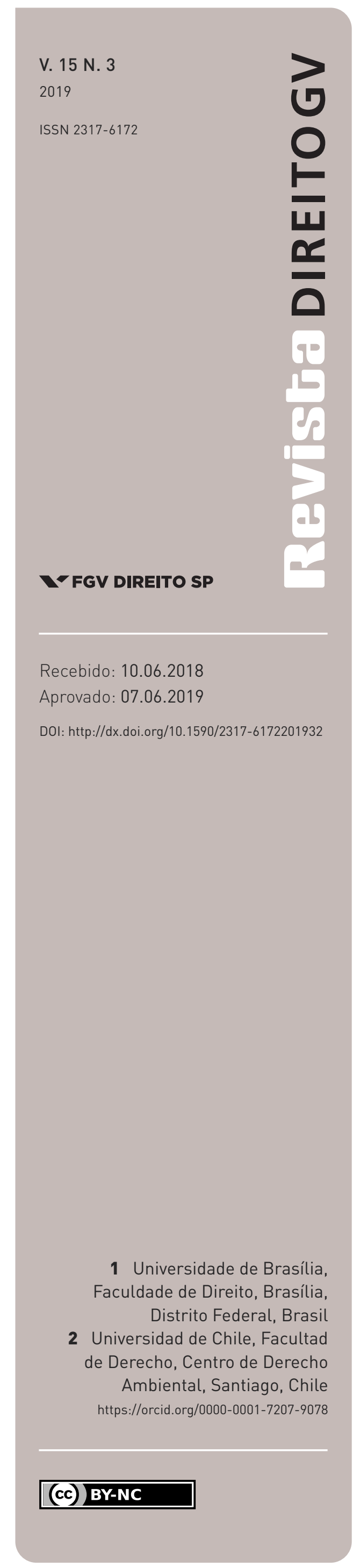

\section{La falibilidad de la captura del Estado en la evaluación de impacto ambiental en Chile}

STATE CAPTURE FALLIBILITY IN ENVIRONMENTAL IMPACT ASSESSMENT IN CHILE

A FALIBILIDADE DE CAPTURA DO ESTADO NA AVALIAÇÃO DO IMPACTO AMBIENTAL NO CHILE

Jorge Aranda Ortega ${ }^{1,2}$

\section{Resumen}

Este texto desarrolla una crítica a la inevitabilidad de la captura del Estado, según lo proponen la teoría de la elección pública, en general, y la lógica de la acción colectiva de Mancur Olson, en particular. Para eso, se explican sus deficiencias metodológicas sobre sus predicciones, la evidencia que utiliza y su explicación insatisfactoria del comportamiento estratégico de los grupos. Luego, desde la teoría procesal administrativa de S. P. Croley, se realiza una crítica jurídica a la teoría de la elección pública, para demostrar que esta trata negligentemente los procedimientos administrativos. Después se prueba la falibilidad de la lógica de la acción colectiva usando dos casos de evaluación ambiental ocurridos en Chile; a saber: "El Morro" e "HidroAysén". Se concluye que la captura en la evaluación de impacto ambiental, en los términos expuestos por la lógica de la acción colectiva, es susceptible de fallar en sus predicciones, por no considerar evidencia suficiente sobre los procedimientos administrativos.

\section{Palabras claves}

Derecho ambiental; evaluación ambiental; elección pública; lógica de la acción colectiva; proceso administrativo.

\begin{abstract}
This text develops a critique of State capture inevitability, as proposed by public choice theory in general, and by the logic of the collective action of Mancur Olson in particular. For this, the methodological deficiencies about its predictions, the evidence it uses, and its unsatisfactory explanation of strategic behavior of groups are explained. Then, from administrative procedural theory of S. P. Croley, a legal critique is made to public choice theory, demonstrating that it negligently deals with administrative procedures. Then, the fallibility of the logic of collective action is tested using two cases of environmental assessment occurred in Chile, namely the case "El Morro" and the case "HidroAysén". As a conclusion, the capture in environmental impact assessment, in the terms exposed by the logic of the collective action, is likely to fail in its predictions for not considering enough evidence on administrative procedures.
\end{abstract}

\section{Keywords}

Environmental law; environmental assessment; public choice; logic of collective action; administrative process.

\section{Resumo}

Este texto desenvolve uma crítica à inevitabilidade da captura do Estado, segundo o proposto pela teoria da escolha pública em geral e pela lógica da ação coletiva de Mancur Olson em particular. Para isso, são explicadas as deficiências metodológicas de suas predições, a evidência que utiliza e sua explicação insatisfatória do comportamento estratégico dos grupos. Logo, a partir da teoria processual administrativa de S. P. Croley, realiza-se uma crítica jurídica à teoria da escolha pública, 
demostrando que esta trata negligentemente os procedimentos administrativos. Depois, se prova a falibilidade da lógica da ação coletiva usando dois casos de avaliação ambiental que ocorreram no Chile, sendo eles o caso "El Morro" e o caso "HidroAysén". Conclui-se que a captura na avaliação de impacto ambiental, nos termos expostos pela lógica da ação coletiva, é suscetível de errar nas suas predições por não considerar evidência suficiente sobre os procedimentos administrativos.

\section{Palavras-chave}

Direito ambiental; avaliação ambiental; escolha pública; lógica da ação coletiva; processo administrativo.

\section{INTRODUCCIÓN*}

La captura del Estado, en la evaluación de impacto ambiental, no es inevitable, como lo propone la lógica de la acción colectiva, en el marco de la teoría de la elección pública. Por el contrario, es posible articular una crítica jurídica a dicha explicación económica del derecho. En ese orden de cosas, el presente texto plantea la siguiente pregunta de investigación: ¿Es inevitable la captura del Estado, propuesta por Mancur Olson a propósito de la lógica de la acción colectiva, en la evaluación de impacto ambiental? La respuesta es que no es inevitable, esto es, que la captura es falible en ciertos casos.

Dicha respuesta, a modo de crítica jurídica, descansa en tres afirmaciones. La primera es que la lógica de la acción colectiva, para explicar la captura, contiene defectos metodológicos respecto de las predicciones vagas y poco operativas que realiza, de la evidencia selectiva que usa y de las dificultades que tiene para explicar el actuar estratégico de ciertos grupos. La segunda es que la lógica de la acción colectiva es negligente en el estudio concreto de los procesos administrativos. La tercera, que es posible recabar evidencia inicial en Chile que demuestra la falibilidad de la lógica de la acción colectiva con base en la evidencia de los casos de evaluación de impacto ambiental de "El Morro" e "HidroAysén". Finalmente, se concluye que la captura del Estado no es inevitable, por lo que no puede ser una justificación indubitada para reformas legislativas y constitucionales.

El contexto de este artículo es pensar en la efectividad de los procesos administrativos ambientales de licenciamiento y en su impugnación judicial, y en cómo la independencia de los órganos decisorios y la participación ciudadana permiten alejarse del pronóstico de la captura

* El presente texto es fruto de la investigación desarrollada en mis estudios de doctorado en el Programa de Postgrado en Derecho de la Facultad de Derecho de la Universidad de Brasilia, Brasil. 
del Estado. Pensar que la captura del Estado en materia ambiental es algo que ocurre a todo evento nos lleva a pensar en la futilidad de la Administración Pública y de los procedimientos administrativos asociados, lo que los torna verdaderos escollos al progreso. Por el contrario, el propósito de este texto es demostrar su falibilidad, como un aliciente para justificar la participación ciudadana, a propósito del derecho ambiental, y para cuestionar la lógica de la acción colectiva como argumento para debatir la evaluación de impacto ambiental.

A mayor abundamiento, y en contra de las proposiciones de la lógica de la acción colectiva, la doctrina del derecho ambiental chileno estima como esencial estimular la capacidad de respuesta de la comunidad organizada frente al deterioro ambiental, para lo cual la sociedad afectada directa o indirectamente debe iniciar las acciones necesarias en defensa de la naturaleza (FERNÁNDEZ BITTERLICH, 2013, p. 66). Así, la participación ha sido entendida como una forma necesaria y conveniente de tratar los asuntos ambientales, toda vez que estos incorporan inherentemente elementos de conflictividad, que colisionan con los diversos intereses involucrados (COSTA CORDELLA y MERINO FUENTES, 2011, p. 103). También, a nivel internacional, ha habido una creciente y convergente consideración de la evaluación de impacto ambiental y de la participación pública como un requisito procedimental para la protección de derechos humanos, tales como la vida privada y familiar y la propiedad (CHÁVEZ FICA, 2015, p. 95). En ese orden de cosas, el presente texto contribuye a esta postura, frente a las presumidamente infalibles predicciones de la lógica de la acción colectiva.

Metodológicamente, este texto recaba evidencia en dos precedentes puntuales, a saber, los casos llamados "El Morro" e "HidroAysén", para explicar la falibilidad de la captura del Estado, apelando a un enfoque inductivo. Si bien esta evidencia no es, en modo alguno, conclusiva, es suficiente para desechar la pretendida infalibilidad de la lógica de la acción colectiva y abre terreno a estudios posteriores, que puedan darle mejor precisión a su alcance. Además, en este texto revisaré estrictamente la participación ciudadana desde una perspectiva regulatoria, dentro de lo que se podría denominar un concepto procesal material de la participación ciudadana, y no en términos procedimentales formales, ni como derecho humano, ni tampoco en cuanto un principio jurídico (ARANDA ORTEGA, 2018, p. 47-49).

Para poder entender estas cuestiones revisaré, brevemente, en qué consiste la teoría de la elección pública, y en el seno de ella, la lógica colectiva. Luego desarrollaré las deficiencias teóricas que presenta, para más tarde articular una crítica jurídica desde la teoría procesal administrativa. A continuación, expondré dos casos concretos para demostrar la falibilidad de la lógica de la acción colectiva en la evaluación de impacto ambiental, para finalmente señalar mis conclusiones.

\section{LA ELECCIÓN PÚBLICAY LA LÓGICA DE LA ACCIÓN COLECTIVA: BREVE EXPLICACIÓN DE} SU INJERENCIA EN EL DERECHO AMBIENTAL

La teoría de la elección pública es una explicación que da la teoría de la elección racional para 
la toma de decisiones políticas. Lo que propone es que los tomadores de decisiones intentarán maximizar sus beneficios individuales en cada decisión política que adopten; esto acarrea diversas consecuencias en los estudios legales y políticos (STIGLER, 1971, p. 3).

Esta teoría surgió como una reacción al pluralismo político, que describe el proceso de toma de decisiones como una verdadera competencia entre diferentes grupos o partidos (DAHL, 1961, p. 223-228), organizados o con potencial de organizarse (JORDAN, 2000), siendo el grupo vencedor aquel que tiene el mejor proyecto político, y por ende, el más votado. En la teoría pluralista, el Estado tiene un rol mediador entre los diferentes grupos y debe garantizar la competencia entre ellos (DAHL, 1989, p. 181-185).

La teoría de elección pública, contrariando al pluralismo político, asevera que, en la práctica, los grupos no son una entidad más allá de los sujetos, individualmente considerados, que los componen, por lo que la toma de decisiones políticas es de un tenor individual (BUCHANAN y TULLOCK, 1990, p. 131-191). Así, bajo esta premisa, un senador que vota un proyecto de ley, un elector que va a la urna o un burócrata que debe decidir sobre la autorización administrativa ambiental de un proyecto no lo harán pensando en los beneficios colectivos que tendrán sus respectivas decisiones, sino en los beneficios económicos individuales que las mismas les reportarán, procurando siempre maximizar sus utilidades personales. En este sentido, cualquier elección obedece a un verdadero mercado de toma de decisiones políticas.

Esta teoría puede explicar una multiplicidad de fenómenos políticos y jurídicos, como la cuota obligatoria de los sindicatos (OLSON, 1971, p. 69), el comportamiento del electorado (DOWNS, 1957, p. 49-50), la maximización de la burocracia (NISKANEN, 1975, p. 617 618) y, lo principal para este texto, la captura del tomador de decisión (OLSON, 1971, p. 147-148). Esta última idea es explicada por una idea más específica, circunscrita a la teoría de la elección pública, a saber, la lógica de la acción colectiva, creada por Mancur Olson.

Dicho autor, para explicar específicamente el comportamiento de un grupo con injerencia política, usa como unidad de análisis el comportamiento individual de sus integrantes (HOWLETT, RAMESH y PERL, 2013, p. 39). Su tesis es que los comportamientos de un grupo responden a la suma de comportamientos individuales tendientes a su subsistencia, por lo que, si un grupo carece de incentivos positivos o negativos para orientar el comportamiento de sus miembros en orden a las finalidades colectivas, este tendería a reportar bajos beneficios individuales, hasta hacerlo desaparecer (OLSON, 1971, p. 33-34).

Para justificar la mayor o menor pertinencia de dichos incentivos, Olson realiza una taxonomía de los grupos según su tamaño (OLSON, 1971, p. 46-50). Así, cuanto menor sea el tamaño del grupo, será más probable la cooperación de los miembros dentro de este, dado que, si un miembro no desea cooperar, los demás miembros del mismo notarían esa falta de esfuerzo con un bajo o nulo costo, y podrían compelerlo a aportar mediante un incentivo negativo, como alguna sanción, o con un incentivo positivo, como una recompensa (OLSON, 1971, p. 60-62). 
Por el contrario, es más difícil en un grupo grande asignar incentivos a los incumplidores, pues es difícil determinar si estos han aportado lo suficiente para alcanzar sus fines (OLSON, 1971, p. 35). Aquellos miembros que obtienen beneficios individuales sin aportar son llamados free riders, o polizones. De esta forma, si la proliferación de polizones llega a un punto en que el aporte de sus miembros es mayor que los beneficios individuales que obtienen, estos desistirán de pertenecer al grupo, y este fracasará como organización colectiva (OLSON, 1971, p. 60-62).

Es necesario destacar que Olson, en su taxonomía de grupos, destaca los llamados grupos privilegiados. Se trata de aquellos en los que uno o pocos miembros tienen un gran incentivo para obrar en pro de la consecución de beneficios que les son muy rentables, sin importarles la existencia de polizones en el grupo (OLSON, 1971, p. 49-50). Los grupos privilegiados serán llamados grupos de interés especial, siempre que actúen en la consecución de sus objetivos perjudicando a los individuos que se encuentran fuera del grupo. Por ejemplo, son grupos de interés especial ciertos gremios empresariales que efectúan lobby en el Congreso para obtener leyes favorables a sus propósitos, en desmedro de los demás ciudadanos (OLSON, 1971, p. 143). Luego, los grupos de interés especial, en la medida en que actúen ofreciendo beneficios a los diferentes tomadores de decisión, dirigirán el actuar de estos a su favor, controlando así los diferentes órganos. Esto es lo que se denomina captura del Estado.

La captura se muestra como un inevitable axioma, cual argumentación algebraica. ${ }^{1}$ Desde una perspectiva jurídica, sería inevitable en una sociedad democrática, porque el restringir la proliferación de grupos de interés especial sería, prima facie, atentatorio al derecho fundamental a reunión. Desde una perspectiva económica sería inevitable porque, dentro un grupo privilegiado, existe un enorme incentivo para que los miembros más favorecidos aumenten sus beneficios mediante la captura de los tomadores de decisión, con independencia del actuar de los demás miembros (incluidos los polizones), lo que hace muy difícil que estos establezcan controles al interior del grupo, pues, si lo hicieren, dejarían de percibir cuantiosas ganancias derivadas de la captura.

En términos teóricos, podemos emparentar a la lógica de la acción colectiva con las teorías que estudian aplicaciones de la economía en el derecho (COASE, 1993, p. 251-253), al alero del realismo jurídico (FARBER, 2001, p. 302-303). En estos estudios, la preocupación de los teóricos es explicar el derecho como realidad a partir de herramientas metodológicas prestadas de la teoría económica. Por ejemplo, desde esta perspectiva cobran sentido el

1 Ello puede ser, por ejemplo, revisado a modo de resumen en: (OLSON, 1982, p. 31-32). Adicionalmente, no podemos perder de vista que el álgebra moderna surgió en parte de la retórica, entendida esta última como una forma de orden lógico del pensamiento. Véase: (CIFOLETTI, 2006a, p. 386-389) y (CIFOLETTI, 2006b, p. 420-423). 
análisis económico del derecho (DEVLIN, 2010, p. 171-173; COOTER y ULEN, 1988, p. 8-13), el nuevo desarrollismo (MATTEI, 2013, p. 43-50), la teoría de los orígenes (NORTH, 1991, p. 108-111), los estudios de derecho y finanzas (PISTOR, 2013, p. 328-329) o el análisis jurídico de la política económica (FARO DE CASTRO, 2009, p. 61-62).

La lógica de la acción colectiva soluciona el problema de la captura con la disminución de la injerencia del Estado, y, consecuencialmente, la disminución de regulación. Así, en la medida que los órganos de la administración del Estado tengan mayor capacidad decisoria, mayor será el mercado de la toma de decisión, habiendo mayores posibilidades de captura. Por el contrario, un Estado pequeño, pero eficiente, sería el ideal buscado.

Estas cuestiones afectarían profundamente el entendimiento del derecho ambiental tal y como lo conocemos, y, con ello, las diferentes técnicas de autorización ambiental, llamándose peyorativamente "lomos de toro" desde esta perspectiva, cuales obstáculos al crecimiento. ${ }^{2}$ En este orden de cosas, si se asume la lógica de la acción colectiva a ultranza, el estudio del derecho ambiental se reduciría al de una agenda legislativa y regulatoria de disminución de la injerencia del Estado en el licenciamiento ambiental, y en la simplificación de los procesos administrativos con la finalidad de disminuir el mercado de la toma de decisión. No en vano, el derecho ambiental es muy sensible a este tipo de abordajes que relacionan el derecho y la economía, pues buena parte de los procesos administrativos estudiados por él son instrumentos de gestión ambiental, que, a su vez, responden a justificaciones económicas (DE MORAES, 2009, p. 165-197).

Con todo, la lógica de la acción colectiva ha sido blanco de críticas. Para efectos de este texto, podríamos clasificarlas en dos tipos: unas que recaen sobre sus aspectos metodológicos, y otras de orden jurídico, que recaen sobre su incapacidad de asumir la imprevisibilidad de los procedimientos administrativos. Revisémoslas a continuación.

\section{CRíticas metodológicas A la lógicA de la ACCiÓn COleCtiva}

La obra de Olson detenta la pretensión de crear, con la lógica de la acción colectiva, una teoría científica que logre explicar el comportamiento de los grupos organizados de forma irrefutable (OLSON, 1971, p. 160 ). Así, la fortaleza de una teoría descansa en la gran capacidad de casos que consiga describir (CROLEY, 2008, p. 11; OLSON, 1982; THAGARD, 1978, p. 79). Es posible comprender estas aseveraciones porque los economistas, metodológicamente, son capaces de obviar el análisis de ciertos hechos con la finalidad de simplificar la realidad, lo que les permite crear modelos con cierta capacidad predictiva (HOOVER, 1995, p. 733; BLAUG, 1985, p. 702; FRIEDMAN, 1966, p. 14-15; ROBBIN, 1932, p. 118-119).

2 Véase, a modo de ejemplo, el empleo de esta infeliz expresión en: (VILLALOBOS, 2017; NAVIA, 2006). 
En atención a ello, la primera crítica que se le puede realizar a la lógica de la acción colectiva es a su metodología, basada en la elección racional individual. A partir de esa idea, se pretende crear una ley de comportamiento universal para expresar el actuar político, y, consecuencialmente, el derecho.

Esta simplificación metodológica asume que todos los individuos, en su desempeño político, actúan racionalmente procurando la maximización de sus utilidades; todos ellos obran de igual forma, sin importar su biografía, historia, cultura u otro tipo de vicisitudes, y sin mayores pruebas al respecto. Esto es, asume una visión universalista de la política, con poca atención a la evidencia de sus postulados (GREEN y SHAPIRO, 1994, p. 2). En este contexto, la investigación empírica se utiliza para salvar o reivindicar alguna variante de la teoría de la elección racional, en lugar de dar cuenta fielmente de un conjunto específico de fenómenos políticos (GREEN y SHAPIRO, 1994, p. 6). Así, los seguidores de la elección públi$\mathrm{ca}$, en general, en lugar de resolver estas cuestiones reformulando sus hipótesis, eluden las evidencias críticas, considerándolas como elementos anómalos a sus postulados, creyendo que, de esa manera, han "salvado" a la teoría, siendo que no han reformado sus hipótesis en específico (GREEN y SHAPIRO, 1994, p. 37-38).

Puedo señalar que la crítica a la acción colectiva acá abordada responde a tres aspectos: a sus predicciones, que son escurridizas y vagas; a la evidencia que la sustenta, que es insuficiente o selectiva, y a que no explica el comportamiento estratégico de diferentes actores, que no son motivados por un mero beneficio individual. A continuación, revisaré rápidamente estas críticas.

\section{I. Predicciones escurridizas y vagas}

Las predicciones de la teoría de la elección pública son escurridizas, pues descansan sobre un elenco de entidades no observables, tales como preferencias, creencias, reglas de decisión y equilibrios óptimos; todo ello, en un alto grado de abstracción (GREEN y SHAPIRO, 1994, p. 38). Luego, se crea un desfase entre la abstracción de sus presupuestos y su formulación concreta, lo que hace que la comprobación de las hipótesis sea compleja y las torna escurridizas (GREEN y SHAPIRO, 1994, p. 38).

Por ejemplo, en la lógica de la acción colectiva, una entidad que determina las bases del modelo son los grupos. Sin embargo, la determinación del tamaño de un grupo es, prima facie, abstracta. ¿Cuántos miembros, como mínimo, debe tener un grupo privilegiado? Olson los determina según su comportamiento, pero... ¿Cómo un comportamiento puede arrojar una cifra exacta de número de miembros? Se podría, con todo, crear una muestra según el comportamiento de los grupos y no según la cantidad de miembros; pero ahí se volvería al estudio de los presupuestos de la teoría, y no de sus predicciones, verificándose así el abismo entre la realidad y lo que se pretende demostrar.

Estas predicciones, además, son vagamente operativas, dado que sus presupuestos abstractos deberían entregar como producto predicciones generales, sin ofrecer resultados empíricamente 
detallados. Sin embargo, ocurre lo contrario: existen, en la literatura de la elección pública, predicciones que son bastante concretas; sin embargo, dada la generalidad de los presupuestos, cuesta imaginar escenarios concretos de aplicación, haciéndolas vagamente operativas (GREEN y SHAPIRO, 1994, p. 41).

A modo de ejemplo, y volviendo a Olson, todo grupo que no considere incentivos para evitar polizones estaría destinado a ser efímero y desaparecer (OLSON, 1971, p. 159-165). En este caso, la predicción se basa en el equilibro de mantener cada unidad marginal de beneficio como equivalente a una unidad de esfuerzo individual, y, en caso de que sea mayor el esfuerzo que el beneficio por causa de los polizones, el grupo se haría inoperativo hasta desaparecer. Con todo... ¿Hay un baremo concreto para probar que todas las organizaciones exitosas cumplen con ese equilibrio, y consecuencialmente, determinar cuáles organizaciones gozan de "buena salud” y cuáles no? No se ofrecen ni ese baremo concreto ni esa prueba subyacente.

\subsection{EVIDENCIA INSUFICIENTE Y SELECTIVA}

También la lógica de la acción colectiva se basa en la búsqueda de evidencia selectiva, ajustada a las predicciones que se desean justificar, siendo ejemplos de sus modelos y no pruebas a las que son sometidos (GREEN y SHAPIRO, 1994, p. 42). Así, sus teóricos ofrecen casos concretos selectos, dejando fuera un amplio espectro de otras evidencias.

Cabe agregar que las investigaciones también son selectivas, orientadas a sostener los presupuestos de la elección pública en lugar probarlos (GREEN y SHAPIRO, 1994, p. 42). En ese sentido, por ejemplo, Olson nunca efectuó investigaciones de grupos que aparentemente careciesen de organización. Por el contrario, podemos identificar en la obra de Ostrom un estudio completo de ellos para desmentir la tesis de Olson (OSTROM, 1990).

En complemento también se incurre en la imaginación de un dato consistente con la lógica económica, asumiendo que este dato está verificado empíricamente, de forma automática (GREEN y SHAPIRO, 1994, p. 44). Por ejemplo, Olson asume un comportamiento egoísta e individual de los miembros del grupo, negando de plano el altruismo, pese a la evidencia científica de divulgación popular en su contra. ${ }^{3}$

La lógica de la acción colectiva también restringe arbitrariamente su ámbito. En ese sentido, sus teóricos establecen ámbitos arbitrarios para la demostración de sus postulados,

3 En contra de los presupuestos de Olson, y desde una perspectiva descriptiva del comportamiento general y sin pretensiones morales, es interesante la explicación sobre algunas especies para perseverar en su procreación, basada en el denominado "gen egoísta”. Según esta, existe un interés egoísta de un individuo por hacer preservar sus genes en las futuras generaciones, genes que también son compartidos por otros miembros de su especie. Entonces, es posible verificar actos altruistas en algunas especies, incluso suicidas, que permiten vivir a sus congéneres, preservando así los genes propios y que comparten con ellos (DAWKINS, 1989, p. 88-108). 
usando recortes que los favorecen y descartando la experiencia que arroje resultados en contra. Así, en lugar de haber una especificación del ámbito relevante debido a condiciones limitantes, hay una especificación del dominio relevante solo a ámbitos en los que la teoría parece funcionar (GREEN y SHAPIRO, 1994, p. 45). Si ejemplificamos ello con Olson, aun pudiendo explicar detalladamente y con toda la evidencia posible el lobby de los gremios de la producción, la lógica de la acción colectiva sería incapaz de explicar el comportamiento electoral del llamado voto protesta, pues, en él, los individuos concurrirían a una actividad que no les reportaría beneficio personal alguno. ${ }^{4}$

\section{Dificultades Para eXPlicAR El COMPORTAMIENTO ESTRATÉGiCO}

Ciertamente, como consecuencia de los recortes selectivos mencionados, la lógica de la acción colectiva también es incapaz de explicar el funcionamiento de los grupos que operan sin que sus miembros individualmente considerados obtengan algo a cambio. ¿Cómo explicar el activismo, o incluso el funcionamiento del Ku Klux Klan? La respuesta no está en el estudio del comportamiento individual bajo los supuestos de la acción racional, sino en el comportamiento estratégico desarrollado por un grupo para alcanzar sus fines (GREEN y SHAPIRO, 1994, p. 77). Es ahí donde la investigación empírica debería prestar atención a efectos de cuestionar la lógica de la acción colectiva.

Para solucionar esas críticas metodológicas a la lógica de la acción colectiva, desde un aporte jurídico, cabría al menos hacer una revisión de la evidencia sobre sus predicciones y sobre el comportamiento estratégico de los grupos en contextos jurídicos, como puede ser un procedimiento administrativo. Si bien la muestra de casos presentada en este texto no es total, si evidencia la falibilidad de la tesis que la lógica de la acción colectiva pretende levantar. Con todo, cabe estudiar la pertinencia de estas predicciones en el contexto del proceso administrativo, lo que nos ayudará a perfilar la crítica jurídica a la lógica de la acción colectiva.

$4 \quad$ Un caso llamativo de convocatoria electoral irracional fue la victoria del luchador retirado Jesse Ventura en la elección para gobernador en el estado de Minnesota, Estados Unidos, en el año 1998. Representando un perfil atípico, fuera de las redes de los políticos profesionales, logró que el electorado lo apoyase sin mayor motivo que ser ajeno a la clase política (BELLUCK, 1998). Situación similar puede ser constatada en Brasil con el comediante Francisco Everardo Oliveira Silva, conocido como "Tiririca", quien fue elegido diputado federal el año 2010 (GUEDES CRESPO, 2010). Adicionalmente, este fenómeno de votar por un candidato ajeno a la llamada política tradicional, por razones irracionales a los ojos de la lógica de la acción colectiva, fue denominado como "efecto Jesse Ventura" por el periodista Michael Moore, en una profética columna que anunciaba la victoria de Donald Trump en la elección presidencial de los Estados Unidos del año 2016 (MOORE, 2016). 


\section{UNA CRÍTICA JURÍDICA A LA LÓGICA DE LA ACCIÓN COLECTIVA}

Es posible establecer dos críticas, desde el derecho, a rasgos generales de la lógica de la acción colectiva. La primera es que se no puede asegurar anticipadamente el resultado exacto de un procedimiento, dado que el mandato judicial es un contrato de medios (y no de resultados) (VIDAL OLIVARES y BRANTT ZUMARÁN, 2013, p. 415), no satisfaciéndose así, prima facie, las pretensiones de la teoría de la elección pública. El resultado de un procedimiento es incierto, sin perjuicio de la creación de modelos de predicción. ${ }^{5}$ Es más, es reñido con la ética profesional de un abogado asegurar a un cliente el resultado de un juicio. ${ }^{6}$

La segunda crítica general es que el análisis de la lógica de la acción colectiva descuida el estudio empírico del iter decisorio. La elección pública se plantea en oposición al pluralismo; pero nunca se ha planteado a sí misma en oposición a la concepción, siquiera formal, del proceso administrativo. Es más, lo ignora totalmente (CROLEY, 2008, p. 73-74).

Para introducir las cuestiones procesales, es menester recordar que una teoría es exitosa en la medida que sea capaz de predecir la mayor cantidad de casos posibles. ${ }^{\mathbf{7}}$ Sobre esa premisa, Croley pretende levantar la teoría procesal administrativa como una respuesta a la teoría de la elección pública, en general, y a la lógica de la acción colectiva, en particular. En pocas palabras, apunta a explicar por qué la captura de los órganos de la administración del Estado por parte de grupos de interés especial no es algo inevitable, o al menos, irrefutable, centrándose en el estudio de casos del proceso regulador estadounidense.

Para efectuar su crítica, Croley logra sintetizar las predicciones de la captura en dos: la primera es una predicción sustantiva, en la cual los grupos de interés especial dirigen las políticas públicas en el sentido que les acomode. La segunda es una predicción procesal, según la cual, ya determinada la política pública, estos grupos dirigen la toma de decisiones de la administración en los diferentes actos administrativos que implementan la política (CROLEY, 2008, p. 22-24).

Luego, sistematizando la captura, propone una secuencia de cinco afirmaciones que explicarían una "cascada"8 en el actuar de los grupos de interés especial, incidiendo desde el nivel

$5 \quad$ En particular, la jurimetría es una rama interdisciplinar de estudios estadísticos y jurídicos, la que aplica metodología cuantitativa al estudio de los diversos procesos, buscando patrones predictivos. Para mayor información véase: (JAEGER ZABALA y FEIJÓ SILVEIRA, 2014, p. 90-94; DE MULDER, VAN NOORTWIJK y LIA, 2010; LOEVINGER, 1949, p. 489-490).

6 Al menos, el Código de Ética Profesional del Colegio de Abogados de Chile, en su artículo 12, literal a, señala “...En particular, al abogado está prohibido: prometer resultados que no dependan exclusivamente de su desempeño profesional”.

$7 \quad$ Supra. Sección 2.

8 Croley no utiliza la expresión “cascada”. La he introducido con finalidades explicativas. 
de decisión más alto al más bajo (CROLEY, 2008, p. 27). La primera de las afirmaciones es sobre el grupo de interés. Según esta, la organización de estos grupos se crea en resguardo del interés individual de cada miembro. No existe un interés colectivo más allá del beneficio de cada sujeto, por lo que el actuar del grupo apunta a la obtención de ganancias que serán aprovechadas individualmente (CROLEY, 2000-2001, p. 16).

La segunda afirmación es sobre la lógica de la acción colectiva. Esta determina que los grupos de interés especial que inciden en la captura son grupos pequeños y privilegiados. Recordemos que los grupos pequeños tienen costos operativos bajos, dado que es muy fácil fiscalizar a cada miembro. Además, como son grupos que tienen poder económico, tendrían ventajas para proceder a la captura del Estado (CROLEY, 2000-2001, p. 16).

La tercera afirmación es sobre la motivación del legislador. Según esta, los grupos de interés especial incidirán primero en el poder legislativo, para influir en la dictación de leyes que les favorezcan. Así, apelarán al mercado de la toma de decisión, apoyando a ciertos legisladores a cambio de la obtención de favores en el Congreso. Por ejemplo, diferentes grupos de interés financiarán las campañas electorales de determinados parlamentarios, pidiendo a cambio que voten apoyando ciertos proyectos de ley (CROLEY, 2000-2001, p. 16).

La cuarta afirmación es sobre la supremacía del legislativo. Una vez que los grupos de interés especial logran capturar el poder legislativo, deben proceder a hacer efectiva la captura "aguas abajo". Así, para lograrlo, los grupos de interés especial dirigen las leyes que rigen el actuar de la Administración en favor de sus intereses. Un ejemplo de esto es la Ley de Presupuestos, pues un órgano que sea díscolo a la agenda que favorece a los intereses privados al final del ejercicio fiscal podría encontrarse con recortes presupuestarios (CROLEY, 2000-2001, p. 16).

La quinta y última afirmación es el favoritismo de la agencia. Estando constreñidos los órganos de la Administración del Estado a favorecer a los grupos de interés especial, estos actuarán con una clara tendencia en contra del interés público (CROLEY, 2000-2001, p. 16).

Según esta "cascada” de afirmaciones, la captura aparece como una cuestión inevitable. Sin embargo, Croley señala que está sostenida por tres presunciones teóricas que son, al menos, cuestionables. La primera es que los grupos se estructurarían en torno al óptimo de Pareto, derivando de este que la contribución de cada miembro es equivalente a los beneficios que obtiene. Sin embargo, y en consonancia con las deficiencias metodológicas expuestas anteriormente sobre evidencia selectiva, no existen pruebas ni cuantificación empírica de ello, y aún más, dentro de su tipología puede haber grupos en que los beneficios no se condigan con los aportes de sus miembros (CROLEY, 2008, p. 31).

La segunda presunción teórica cuestionable es que no todos los grupos actúan debido a una conjunción de intereses individuales, lo que corrobora la crítica metodológica sobre la falta de explicaciones sobre el actuar estratégico. Por el contrario, puede haber elementos morales que motiven el actuar colectivo y operen como catalizadores del actuar de los grupos. De otra forma, sería difícil explicar el actuar altruista (CROLEY, 2008, p. 34-35). En 
ese sentido, no todo interés es necesariamente egoísta; es posible que el actuar de un grupo procure la realización del bien común (CROLEY, 2008, p. 39).

La tercera crítica es que los congresistas no son inmunes a la reacción del electorado. El hecho de que sean capturados no garantiza que siempre sean electos, pues decisiones impopulares les restarían apoyo, impidiéndoles tener éxito en los próximos comicios. El interés individual de cualquier congresista sería permanecer el mayor tiempo posible en su escaño, intentando mantener la lealtad del electorado. De esa forma, adoptar solo decisiones que afecten al interés público, en favor de los grupos de interés privado, sería un camino que impediría su reelección en el futuro (CROLEY, 2008, p. 38).

Luego, podemos entender que estas tres críticas recaen sobre la evidencia que sustenta a la lógica de la acción colectiva, sobre los valores metaindividuales que ignora, y sobre las influencias que sufren los congresistas más allá de los grupos de interés especial. Debido a estas tres críticas, las cinco afirmaciones antedichas son refutables (CROLEY, 2008, p. 50). Por ejemplo, es posible constatar que hay organizaciones que no responden solo a intereses individuales, como es el caso del activismo. Estas responden al llamado interés púbico, refutando así la afirmación sobre los grupos de interés. Además, ante la falta de evidencia o de parámetros exactos sobre la cantidad de miembros que requiere una organización para ser privilegiada, los contornos prácticos de la teoría se van desdibujando.

Entonces, si la afirmación de la lógica de la acción colectiva fuera irrefutable, no sería posible que organizaciones de gran tamaño, que buscan la realización de un interés público, tuviesen cabida en el mundo real. Si así fuese, organizaciones como Amnistía Internacional serían contrarias a las predicciones de la lógica de la acción colectiva (CROLEY, 2000-2001, p. 18-19).

Además, es posible criticar la afirmación de la motivación del legislador, pues los congresistas pueden responder también a elementos de valor ajenos a grupos de interés especial. Así, si grupos organizados logran posicionarse, y son capaces de denotar las faltas de un congresista ante los votantes, este se arriesgaría a no ser reelegido en el futuro (CROLEY, 2000-2001, p. 20-21).

La afirmación de la supremacía del legislativo también se vería afectada, en la medida en que los legisladores se arriesguen a perder electorado, ya que en casos sensibles tenderían a interferir poco o nada en el actuar de las agencias, so pena de terminar perdiendo su reelección. De esta forma, en la medida en que se levanten ciertas agendas de valor con alto apoyo popular, los congresistas tendrán menor margen para constreñir a las agencias (CROLEY, 2000-2001, p. 22).

En adición, también quedaría en entredicho la afirmación del favoritismo de las agencias. En la medida en que los constreñimientos legislativos sean menores, mayor será la independencia decisoria de estas y, así, queda abierta la posibilidad de que no sean capturadas a todo evento.

Entonces, quedando en entredicho las cinco afirmaciones de la elección pública, en el proceso administrativo los interesados interactúan contraponiendo sus intereses a los de los grupos de interés especial, encontrando ahí fuentes para levantar evidencia y apreciar cómo operaría 
(o no operaría) en la práctica la lógica de la acción colectiva. Así, Croley propone una teoría comprensiva que incorpora varios elementos que causan efectos de un ámbito a otro (CROLEY, 2008, p. 71). En ese sentido, las instancias políticas y administrativas, más que responder a verdaderos túneles de una entrada y una salida (o input-output, si se quiere), son más bien un iter de varias posibilidades.

Recogiendo las críticas sobre evidencia, valores metaindividuales e influencias más allá de los grupos de interés especial, Croley reformula la "cascada" que propuso para explicar la captura y determina una nueva sucesión de afirmaciones causales. La primera afirmación es la motivación de la administración: no es inevitable que la administración siempre esté constreñida. Por el contrario, en los procesos administrativos, es posible que desde la participación ciudadana se recojan concepciones afines al interés público, contrariando a los grupos de interés privado (CROLEY, 2008, p. 73).

La segunda afirmación es sobre la autonomía de la agencia. Según esta, la falta de constreñimiento hacia las agencias, y estas pudiendo recoger así las opiniones ciudadanas, se explica porque no siempre el comportamiento de la Administración estaría determinado por leyes dictadas por congresistas capturados. Así, algunos resguardos institucionales adicionales, como la autonomía presupuestaria, dan pie a que, eventualmente, las agencias puedan tener mayor ámbito para desenvolverse (CROLEY, 2008, p. 73).

La tercera afirmación es la del ambiente institucional. Los congresistas, a su vez, no determinan efectivamente el comportamiento de las agencias, porque, incluso siendo financiados o apoyados por grupos de interés privado, también son susceptibles de recibir otro tipo de influencias, especialmente de grupos articulados en torno a valores. Así, los congresistas, en ciertos casos, no se arriesgarían a ser impopulares y hacer peligrar su reelección (CROLEY, 2008, p. 73-74).

La cuarta afirmación es la neutralidad de la administración. Esta asevera que, existiendo influencias tanto de grupos articulados por valores como de grupos de interés especial, a la administración le cabe mediar entre estas disputas, dejándole un margen menor para ser capturada. Luego, la presión de los grupos articulados por valores se haría sentir a través de diferentes medios, como mecanismos judiciales de impugnación, o mediante la presión de congresistas que comulguen con esas agendas (CROLEY, 2008, p. 74).

La última y quinta afirmación es la del bienestar social. Ante la presión de diversos actores, la motivación de las decisiones administrativas sobrepasaría los requisitos meramente formales, debiendo justificar por qué se decide en una dirección o en otra. En ese sentido, el proceso habilitaría a las agencias a determinar, en los hechos, resultados socialmente deseables (CROLEY, 2008, p. 74).

Para que esta sucesión de afirmaciones sea posible, Croley logra identificar cuatro factores: la información, la participación ciudadana, la estabilidad laboral de los funcionarios de la administración y la revisión judicial de los actos administrativos terminales (CROLEY, 2008, p. 136). Me referiré con alguna detención a la información y a la participación ciudadana. 
Sobre la información, es fundamental tener presente que, gracias a los datos, se pueden perfilar los hechos regulados, siendo el principal elemento para convencer a los diferentes actores de cómo normar una determinada cuestión. Cabe señalar también que la información no es fungible, como pueden serlo el dinero o los votos, sino que esta debe ser pertinente e inteligible a los efectos regulatorios deseados. ${ }^{9}$

Con relación a la participación ciudadana, esta es muy importante para que las agencias puedan recopilar información adicional, acrecentando datos, y así mejorar el entendimiento que se tiene sobre el asunto. Recuérdese que la participación es también un derecho de los ciudadanos; es menester del Estado crear reglas que hagan transparente y disponible la información (CROLEY, 2008, p. 138-142).

Volviendo a los cuatro factores antedichos, estos determinan que la sucesión de las cinco afirmaciones virtuosas pueda ocurrir en la vida real y, con ella, exista una buena regulación. El adjetivo "bueno" estaría determinado por atender a un interés público, el cual no es un constructo teórico abstracto, sino aquello que se estima socialmente deseable, luego de la conjugación de diferentes intereses en un procedimiento administrativo (CROLEY, 2008, p. 308-306).

Adicionalmente, Croley se preocupa de determinar, con evidencias de procesos de creación de regulaciones de los Estados Unidos, la falibilidad de la teoría de la elección pública. ${ }^{10}$ De esta evidencia concluye que el estudio de casos le deja un soporte considerable a la teoría procesal administrativa. En particular, muestra que las agencias lograron, por medio de diferentes procedimientos, resguardarse de diferentes presiones de grupos de interés especial, y

9 Si bien este aspecto no es abordado por la teoría procesal administrativa, la captura puede ocurrir también por el exceso de información aportada por los grupos de interés especial, siendo esta difícil de ser procesada por la Administración y por los otros interesados (WAGNER, 2010, p. 1325; COHEN, 2016, p. 370-375; ANDREJEVIC, 2013, p. 11-44).

10 Los ejemplos que usa Croley son los siguientes: el caso de la formulación de la regulación de ozono, realizado por la Agencia de Protección Ambiental (CROLEY, 2008, p. 163-179); el caso de la regulación para disminuir el consumo de tabaco, realizado por la Administración de Comidas y Drogas (CROLEY, 2008, p. 180-195); el caso de la regulación para prohibir la construcción de carreteras en áreas protegidas forestales, efectuado por el Servicio Nacional Forestal (CROLEY, 2008, p. 196-212); el caso de la regulación de la publicidad telefónica, conformado por la Comisión Federal de Comercio (CROLEY, 2008, p. 214-221); el caso de la regulación de la venta de seguros para cubrir eventos de mala praxis legal de los abogados, guiado por la Comisión de Bolsa y Valores (CROLEY, 2008, p. 221-228); y, finalmente, el caso de la regulación para liberalizar los bancos para vender productos derivados, como seguros, realizado por la Oficina Contralora de la Moneda (CROLEY, 2008, p. 228-236). En general, en estos casos, se puede apreciar que las predicciones de la lógica de la acción colectiva, respecto de la captura realizada por los grupos de interés especial, no ocurre. Con eso, Croley levanta evidencia jurídica que contraría a las proposiciones de Olson, demostrando su posibilidad de ser falible. 
que las mismas tuvieron motivaciones encaminadas al bienestar público, encarando así intereses contrarios (CROLEY, 2008, p. 282).

Cabe agregar, para un correcto entendimiento de las ideas de este autor, que la independencia debe verificarse tanto en el procedimiento administrativo propiamente dicho, como en los mecanismos de impugnación judicial del mismo, siendo, ciertamente, los tribunales también garantes de evitar la captura, mediante la litigación de la ciudadanía contra los grupos de interés especial (CROLEY, 2008, p. 140-142). En este orden de cosas, los cuestionamientos a la captura no solo pasan por la falibidad de un órgano adminisrativo, o de un poder del Estado en particular, sino por el conjunto de los procesos legislativo, administrativo y judicial. Así, un poder judicial ciertamente independiente también tiene un rol fundamental para evitar la captura del Estado, como se podrá apreciar más adelante en el caso "El Morro"."11

Con base en esta evidencia jurídica, Croley logra criticar la lógica de la acción colectiva, al demostrar que esta no ha podido superar las críticas efectuadas de manera determinante. Respecto de la evidencia, destaca que la lógica de la acción colectiva ha sido negligente en tratar los procesos administrativos, su tramitación, impugnación y resultados.

A mayor abundamiento, dado que es relevante dentro de la teoría procesal administrativa de Croley la autonomía del órgano tomador de decisión gracias al procedimiento administrativo, es conveniente tratar la conformación orgánica del mismo, en lo que se podría denominar diseño institucional. Según estas ideas, se apunta a que no es suficiente con la recta ordenación formal de los procedimientos, dado que la configuración de los órganos puede determinar diversos resultados (IMMERGUT, 2006, p. 561), en una suerte de dependencia de la trayectoria institucional en la regulación, a lo largo del tiempo (PIERSON, 2000 , p. 259). Así, en la práctica, el impacto de los procedimientos depende también de las estructuras políticas locales, y no simplemente de reglas formales (IMMERGUT, 2006, p. 565).

Ciertamente, las cuestiones de diseño institucional, desde el punto de vista legal, surgen para resolver la superación de la división estricta de las funciones ejecutiva, legislativa y judicial, creando así complejos arreglos institucionales de frenos y contrapesos. En el caso particular de los órganos con autonomía, estos sustituyen o complementan la función legislativa en cuestiones de complejidad técnica (CALABRESI, BERGHAUSEN y ALBERTSON, 2012, p. 438-442). Así, la conformación de cuerpos descentralizados, agencias o formaciones antimayoritarias, si se quiere, obran, paradójicamente, en favor de los intereses de los ciudadanos, pero sin el control directo que tienen los órganos democráticamente elegidos (MELO, 2005, p. 202), logrando gestionar asuntos públicos con mayor eficiencia, y también,

Infra. Sección 5.1. 
solucionando imperfecciones de la estricta división de poderes, en particular las devenidas de su estrechez pragmática (ROSSI, 2001, p. 557-558).

Para garantizar la autonomía desde el punto de vista legal, en el derecho estadounidense, la configuración orgánica es la agencia reguladora, a saber, un órgano investido con autoridad para regular actividades económicas de los individuos y sus respectivos negocios, mediante el uso de poder normativo, sancionador y de juzgamiento en ciertas situaciones, sin que estos sean el Senado, el Ministerio Público o un Tribunal (SCHWARTZ y WADE, 1972, p. 26). En cambio, en el derecho continental, por lo general, la respuesta para dar mayor autonomía a los órganos de la administración, desde finales del siglo XIX, es mediante órganos con personalidad jurídica diferenciada del fisco y patrimonio propio (MAYER, 1954, p. 254), llamados órganos autárquicos en la doctrina italiana (LENTINI, 1939, p. 77), y órganos descentralizados en la francesa (JEZE, 1949, p. 30). En Chile se recogió esta última nomenclatura (FERRADA BÓRQUEZ, 1999), y es la que predomina en materia ambiental, habiendo discusiones legislativas sobre el punto a la fecha. ${ }^{12}$

Así, respecto de su aproximación jurídica, la lógica de la acción colectiva ha sido negligente en tratar a los procesos administrativos como un mero input-output, y no como lo que realmente pueden ser: una dialéctica en la cual la administración gana autonomía y aumenta la información disponible para la toma de decisiones. También desconsidera ciertos elementos del diseño institucional que dan ciertas garantías de independencia a los órganos. En este sentido, la teoría procesal administrativa es superior a la lógica de la acción colectiva.

A modo de resumen parcial, la teoría procesal administrativa es superior a la lógica de la acción colectiva para explicar la captura del Estado por parte de los grupos de interés especial porque, en primer lugar, trabaja con evidencia que desmiente la predicción de captura inevitable. En segundo lugar, porque da cuenta, de mejor manera, de los elementos jurídicos relacionados al proceso como iter decisorio. Luego, cabría preguntarse si es posible recabar evidencias, siquiera mínimas, para explicar la falibilidad de la captura del Estado en los procesos de evaluación de impacto ambiental. A continuación, pasaremos a revisar brevemente dos casos ocurridos en Chile sobre el asunto.

12 En Chile, la evaluación de impacto ambiental se desarrolla bajo un modelo de coordinación desde la dictación de la ley 19.330/1994 de Bases Generales del Medio Ambiente. En su redacción original, esta ley coordinaba diversos órganos descentralizados con competencias ambientales (en los términos ya señalados, y según lo dispuesto en los artículos 26 y 33 de la Ley Orgánica Constitucional de Bases Generales de la Administración del Estado) mediante otro órgano descentralizado: la Comisión de Nacional del Medio Ambiente a nivel nacional, y mediante las Comisiones Regionales Ministeriales del Medio Ambiente al nivel Regional. Esta Comisión tenía funciones tanto de evaluación ambiental como políticas y de fiscalización, y estaba integrada por jefes de diversas carteras ministeriales. Luego, con las reformas de la ley 20417/2010, se creó un órgano descentralizado, destinado solo a la gestión del Sistema de Evaluación de 


\section{EJEMPLOS DE LA FALIBILIDAD DE LA LÓGICA DE LA ACCIÓN COLECTIVA EN LA EVALUACIÓN DE IMPACTO AMBIENTAL EN CHILE: "El MORRO" E "HidROAYSÉN"}

La captura del Estado, según la lógica de la acción colectiva, debería ocurrir invariablemente. Esta idea, de orden general, también puede aplicarse a los procedimientos de evaluación de impacto ambiental, cuya finalidad es obtener un acto administrativo terminal de autorización para operar una actividad productiva, haciéndose cargo de los impactos ambientales que pueda generar. Así, el proceso de evaluación ambiental sería una instancia para que los tomadores de decisión sean capturados por los titulares de proyecto, para que después autoricen con negligencia actividades contaminantes en perjuicio de la población. Sin embargo, ha habido casos en que ello no ha ocurrido. Por el contrario, la ciudadanía ha logrado articularse y contravenir algunas de esas situaciones.

A continuación, se expondrán dos casos ocurridos en Chile. Uno, relacionado con un proyecto minero llamado "El Morro". El segundo es sobre un proyecto de generación hidroeléctrica llamado "HidroAysén". Revisaré a continuación dichos casos.

\section{I. Caso "El Morro"}

Esta es una buena evidencia de cómo una comunidad logra organizarse y contraponerse a una gran empresa minera. El caso data del año 2008, con el inicio del estudio de impacto ambiental. El proyecto fue impulsado por las empresas Goldcorp y New Gold, diseñado para obtener 2.500 millones de dólares, utilizando un total de 2.363 hectáreas, incluidos los tranques de relave en la comuna de Alto del Carmen, III Región de Atacama (SERVICIO DE EVALUACIÓN AMBIENTAL, 2017a).

En un comienzo, el proyecto estaba pensado para operar con agua desalinizada; pero la empresa estaba, por otra parte, comprando con anticipación derechos de aprovechamiento de aguas a las comunidades locales, las cuales, desde temprano, estaban en oposición al proyecto,

Impacto Ambiental, a saber, el Servicio de Evaluación Ambiental. Este administra el procedimiento administrativo de evaluación de impacto ambiental, dejando la decisión política final a la Comisión de Evaluación dispuesta en el artículo 86, integrada por los Secretarios Regionales Ministeriales de diversas carteras, más el Intendente, o al Director del Servicio, en caso de que el proyecto impacte en dos o más regiones. Luego, en el 2018, se comenzó a tramitar en la Cámara de Diputados un proyecto de ley bajo el Boletín 11952-12, con fecha 31 de julio de 2018, que busca aumentar la autonomía del tomador de decisión, en un intento de despolitizar el acto administrativo terminal, en pro de una mayor tecnificación de la decisión. Se sustituye la Comisión de Evaluación del artículo 86 y al Director del Servicio por Comités Macrozonales, integrados por secretarios ministeriales locales y, como novedad, por dos miembros elegidos mediante el sistema de alta dirección pública. En principio, y si bien se valora esta iniciativa de reforma orgánica que busca mayor autonomía decisoria, hay que denotar, prima facie, problemas respecto de la concentración territorial parcial de la toma de decisión en macrozonas, y una autonomía relativizada, al continuar habiendo una mayoría de miembros designados, directa o indirectamente, por el Presidente de la República. 
siendo estas la comunidad Diaguitas Huascoaltinos, el Consejo de Defensa del Huasco, la Parroquia Nuestra Señora del Carmen y la Coordinadora Ambiental Alto del Carmen (SERVICIO DE EVALUACIÓN AMBIENTAL, 2017a).

La principal preocupación de las comunidades locales era el abastecimiento de agua, pues los proyectos mineros precisan grandes cantidades de recursos hídricos (SERVICIO DE EVALUACIÓN AMBIENTAL, 2017a). En otro sentido, la empresa presentó un proyecto incompleto, esperando presentarlo íntegramente en el transcurso del proceso de evaluación, lo que generó desconfianza en la comunidad (INSTITUTO NACIONAL DE DERECHOS HUMANOS, 2016, p. 96). En ese escenario, las empresas trataron de aproximarse, organizando reuniones con los posibles afectados para obtener algún nivel de respaldo. Estas reuniones fueron rechazadas desde el comienzo (INSTITUTO NACIONAL DE DERECHOS HUMANOS, 2016, p. 96).

El proceso de participación ciudadana ocurrió en una comunidad rural que no tenía la preparación científica y técnica para procesar un estudio de impacto ambiental, que comprendió siete volúmenes de más de 500 páginas cada uno, así como 1.150 documentos anexos (INSTITUTO NACIONAL DE DERECHOS HUMANOS, 2016, p. 96). Cabe señalar que el plazo legal para formular las observaciones, de acuerdo con la legislación chilena, es de 60 días, conforme lo establece el artículo 29 la ley 19.300/1994.

Frente a aquellos grandes obstáculos, las comunidades mantuvieron la cohesión social, pero desarrollando una participación poco contundente en los aspectos técnicos. La mayoría de las observaciones se limitaron a apuntar, en palabras simples, que estarían en peligro las aguas de regadío del valle, la salud humana y animal. Con todo, fueron formuladas más de 312 observaciones (SERVICIO DE EVALUACIÓN AMBIENTAL, 2017a).

Otro punto relevante es que la mayor parte de los interesados eran indígenas y pedían que fuere aplicada la consulta indígena contemplada en el artículo 6 del Convenio 169 de la OIT. Tanto la administración del Estado como las empresas fueron contrarias a este proceso de consulta, porque dicha comunidad no era considerara explícitamente en la ley de desarrollo indígena 19.253/1994.

En el año 2011, la Comisión de Evaluación Ambiental autorizó el proyecto, lo que generó una fuerte oposición en los tribunales superiores de justicia, primero con una acción de protección, que pedía la nulidad de la autorización administrativa, por no permitir en la oportunidad correspondiente una efectiva participación ciudadana, incumpliendo también las obligaciones de la consulta del Convenio 169 de la OIT, la cual fue acogida por la Corte de Apelaciones de Copiapó y luego confirmada por la Corte Suprema. ${ }^{13}$

Sobre la acción de protección cabe recordar, a modo de pequeño excurso, que, si bien hoy existen mecanismos contencioso-administrativos formales creados por la ley 20.600/2012 
(BERMÚDEZ SOTO, 2015, p. 517-519; ASTORGA JORQUERA, 2017, p. 485-487), a la fecha del precedente estudiado éstos no existían, por lo que se usaba, ciertamente de manera impropia y bajo fuertes cuestionamientos (PIERRY, 1977, p. 157-159), la acción de protección como mecanismo de impugnación administrativa. Se sustituía así la falta de un procedimiento contencioso administrativo, aún a riesgo de dar un uso poco adecuado a este procedimiento de urgencia, malinterpretando y vulgarizando derechos fundamentales y su tutela jurídica (FERRADA BÓRQUEZ, BORDALÍ SALAMANCA y CAZOR ALISTE, 2002, p. 81).

Retornando al relato del caso, luego de que los tribunales superiores acogieran la petición de las comunidades indígenas, el titular del proyecto volvió a someter el proyecto a evaluación ambiental, obteniendo una vez más autorización para proceder con el mismo, siendo impugnada con tres acciones de protección por parte de los afectados. ${ }^{14}$ Estas acciones fueron rechazadas en primera instancia, pero finalmente acogidas por la Corte Suprema en el año 2014, la que volvió a anular la autorización, pidiendo realizar, de buena fe, un proceso de consulta indígena. ${ }^{15}$ Las empresas, en octubre de 2014, desistieron de desarrollar el proyecto, frente a un marco normativo que consideraron poco claro (INSTITUTO NACIONAL DE DERECHOS HUMANOS, 2016, p. 96).

Es posible observar en este conflicto que la comunidad, por la falta de apoyo científico y técnico, no logró aportar información suficiente en las primeras etapas de evaluación. Sin embargo, gracias una fuerte cohesión social y un argumento consistente, basado en la necesidad de la consulta del Convenio 169 de la OIT, hubo una oposición en los tribunales superiores de justicia, existiendo una salvaguarda a la captura del Estado en el actuar del poder judicial, y no la Administración misma. También se verifica en el proceso administrativo de evaluación ambiental una asimetría de información entre la empresa y la comunidad.

\subsection{CASO "HidroAysÉN"}

El caso "HidroAysén" correspondió a un proyecto de generación de energía de gran envergadura, consistente en cinco centrales hidroeléctricas a ser construidas en el río Baker, en la XI región de Aysén, afectando a tres comunas: Cochrane, Tortel y O’Higgins. La superficie total a utilizar por los embalses sería de 5.910 hectáreas, con una potencia proyectada de 2.740 MW, y siendo titular del proyecto la empresa HidroAysén S.A., sociedad de Colbún-Endesa. La inversión total sería de unos 3.200 millones de dólares (SERVICIO DE EVALUACIÓN AMBIENTAL, 2017b). El proyecto evaluado consideraba solo la generación de energía eléctrica, pues no contemplaba proyectos de transmisión ni de distribución de la energía generada.

14 Corte de Apelaciones de Copiapó. Rol 250-2012, Rol 151-2013 y Rol 436-2013.

15

Corte Suprema. Rol 8774-2014. 
El proyecto ingresó a evaluación ambiental en el año 2008, y desde un comienzo tuvo resistencias, pues la comunidad se organizó rápidamente por los siguientes actores sociales: Coalición Ciudadana por Aysén Reserva de Vida, Corporación por el Desarrollo de Aysén (CODESA), Comité Nacional Pro Defensa de la Fauna y la Flora (CODEFF), Consejo de Defensa de la Patagonia, Agrupación de Defensores del Espíritu de la Patagonia, Corporación Costa Carrera, Escuela de Guías de la Patagonia, Escuela NOLS, Cámara de Turismo y Comercio de Puerto Río Tranquilo, ONG Ecosistemas, Fundación Conservación Patagónica, Agrupación Nacional Jóvenes Tehuelches, el obispo Luis Infanti y el senador Antonio Horvarth. Todos esos actores, en el proceso de participación ciudadana, lograron formular 10.081 observaciones, en el plazo de 60 días (SERVICIO DE EVALUACIÓN AMBIENTAL, 2017b). Esas observaciones fueron de diferente tenor, siendo algunas de habitantes menos instruidos, de antiguos colonos y de ONG con experticia técnica (INSTITUTO NACIONAL DE DERECHOS HUMANOS, 2016, p. 208).

Igualmente, desde el comienzo de la evaluación, los servicios públicos coordinados por la autoridad ambiental plantearon una gran cantidad de observaciones al proyecto. Por ejemplo, la Dirección General de Aguas formuló 949 observaciones en el primer informe consolidado de evaluación, 114 de la Dirección General de Obras Hidráulicas y 133 del Servicio Nacional del Geología y Minería (SERVICIO DE EVALUACIÓN AMBIENTAL, 2017b).

Así, entre el año 2009 y 2011 la empresa presentó tres addenda para superar las omisiones del proyecto y responder a las observaciones ciudadanas. Aun así, se autorizó el día 9 de mayo de 2011, frente a una fuerte presión social, dados sus impactos ambientales. Al día siguiente, en Santiago, se reunieron 15.000 personas en una protesta, según la información entregada por carabineros, y 70.000, según la información de las organizaciones sociales (INSTITUTO NACIONAL DE DERECHOS HUMANOS, 2016, p. 208).

Después, el proyecto fue impugnado con una acción de protección ante la Corte de Apelaciones de Puerto Montt en el año 2011, la cual denegó la petición de los demandantes, ${ }^{16}$ situación que fue confirmada por la Corte Suprema de Justicia en la respectiva apelación. ${ }^{17}$ Con todo, los representantes de la comunidad perseveraron con un recurso administrativo contemplado en caso de modificaciones al proyecto y por no considerar debidamente la participación ciudadana. Este recurso debería ser resuelto por el Comité de Ministros contemplado en el artículo 20 de la ley 19.300. Dicho Comité resolvió que el proyecto, por no considerar debidamente las observaciones de la ciudadanía, y también por no ofrecer medidas adecuadas de reparación, debería ser anulado, cuestión que ocurrió en junio del 2014 (SERVICIO DE EVALUACIÓN AMBIENTAL, 2017b).

\footnotetext{
16 Corte de Apelaciones de Puerto Montt, Rol 179-2011.

17 Corte Suprema, Rol 10220-2011.
} 
Revisando el proceso de participación ciudadana, en este caso, existió una fuerte oposición a los grupos de interés especial desde una comunidad organizada. Acá, la comunidad contó con apoyos y recursos económicos, con articulaciones políticas y sociales fuertes, que permitieron desarrollar incluso un acto masivo de protesta. También, en este caso, los tribunales no interfirieron mayormente en la decisión administrativa, denegando las peticiones de la acción de protección, pero, finalmente, y bajo la presión ciudadana, el Comité de Ministros dejó sin efecto la autorización.

\section{CONCLUSIONES}

Con la evidencia antedicha queda demostrada la falibilidad de la captura de Estado en los términos propuestos por la lógica de la acción colectiva, respondiendo a la pregunta apuntada al inicio del texto, a saber, si acaso la captura del Estado, en la evaluación de impacto ambiental, es inevitable. En este sentido, lo primero que podemos establecer es que, desde la evidencia jurídica, los discursos que desean disminuir los procesos de evaluación ambiental, amparados en ideas del "Estado mínimo", de "desburocratización del Estado", son miopes ante las oportunidades que el proceso administrativo, y su respectiva impugnación judicial, ofrece para evitar la captura de los órganos de la Administración del Estado.

Esta falibilidad viene determinada por las tres cuestiones ya señaladas en el texto. La primera es que la lógica de la acción colectiva tiene defectos metodológicos que no logra salvar, respecto de las predicciones vagas y poco operativas que realiza, de la evidencia selectiva que usa y de las dificultades que tiene para explicar el actuar estratégico de ciertos grupos. En segundo lugar, y usando los elementos teóricos aportados por Croley, queda de manifiesto el negligente tratamiento de los procedimientos administrativos, y sus respectivas impugnaciones judiciales, por parte de la lógica de la acción colectiva. Finalmente, la evidencia mostrada en los casos "El Morro" e "HidroAysén”, pese a no ser conclusiva, es suficiente para dar indicios de la falibilidad de la captura del Estado.

En ese orden de cosas, la discusión sobre la evaluación de impacto ambiental, prima facie, no debe recaer en los simplismos de "más Estado" o "menos Estado", sino en repensar los procesos administrativos de evaluación ambiental, para que los tomadores de decisión detenten mayor autonomía, y para que la ciudadanía tenga mayores potencialidades de participación. Con ello, se abre un camino para salir de las explicaciones jurídicas tradicionales del proceso administrativo ambiental y del contencioso administrativo ambiental, ${ }^{18}$ visando su efectividad contra la captura.

18 Sobre esta visión formal, heredada de la doctrina procesal italiana, véase (ALCALÁ-ZAMORAY CASTILLO, 1992, p. 484; BUZAID, 1977, p. 152). 
Si bien la evidencia del presente texto no es conclusiva, es suficiente para demostrar la falibilidad de la lógica de la acción colectiva. Esta se explica por sus limitaciones metodológicas, sus predicciones incumplidas, su evidencia selectiva e incompleta, y su incapacidad de predecir el comportamiento estratégico de grupos activistas. En el caso particular de los precedentes mostrados, de las comunidades indígenas en el caso "El Morro" y las ONGs y comunidad local en el caso "HidroAysén".

Junto a ello, también es posible proyectar un interesante campo de estudio crítico de las relaciones entre derecho y economía desde la evidencia procesal administrativa. Por una parte, el derecho ambiental como disciplina se ha ocupado de la participación ciudadana como la formulación de un principio jurídico y de su aplicación en abstracto, ${ }^{19}$ descuidándose de contraargumentar a otros abordajes. Por la otra, la elección publica, en general, y la lógica de la acción colectiva, en particular, han sido negligentes al abordar la participación ciudadana en el proceso administrativo. En este texto, sin recabar en evidencias rebuscadas sobre proyectos de alto impacto ambiental, es posible objetar esas predicciones. Este desencuentro de enfoques deja un amplio margen para futuros estudios interdisciplinarios, lo que abre la puerta a la búsqueda de más evidencias afines a esta crítica y contraria visiones de la evaluación de impacto ambiental como un obstáculo al progreso.

\section{AGRADECIMIENTOS}

El autor agradece al Dr. Marcio Iorio Aranha por su invaluable ayuda y orientación. También agradece al Dr. Flavio Bianchi y al Dr. Heitor Simão Afonso Ambrósio por sus oportunos comentarios. Igualmente, agradece al Sr.Juan Pablo Fuenzalida Peñaloza por sus correcciones formales.

\section{REFERENCIAS}

ALCALÁ-ZAMORAY CASTILLO, N. Aportación hispánica a la difusión de la ciencia procesal italiana. In: ALCALÁ ZAMORA, N. Estudios de teoría general del proceso (1945-1972). Ciudad de México: Instituto de Investigaciones Jurídicas, v. II, 1992. p. 479-500. 2003, p. 76; ALENZA GARCÍA, 2001, p. 47; NEUMANN, 1996, p. 86). 
ALENZA GARCÍA, J. F. Manual de derecho ambiental. Pamplona: Universidad Pública de Navarra, 2001.

ANDREJEVIC, M. Infoglut: how too much information is changing the way we think and know. Nueva York: Routledge, 2013.

ARANDA ORTEGA, J. Breve reflexión sobre cuatro conceptos jurídicos de participación ciudadana a propósito del derecho ambiental chileno. Revista de Derecho Ambiental, Santiago, 2018.

ASTORGA JORQUERA, E. Derecho ambiental chileno. 5. ed. Santiago: Thomson Reuters, 2017.

BELLUCK, P. THE 1998 ELECTIONS: THE STATES — THE MAVERICK; A 'Bad Boy' Wrestler's Unscripted Upset. The New York Times, Nueva York, 5 nov. 1998. Disponible en: <http: / / www. nytimes.com/1998/11/05/us / the-1998-elections-the-states-the-maverick-a-bad-boy-wrestler-sunscripted-upset.html>.

BERMÚDEZ SOTO, J. Fundamentos de derecho ambiental. 2. ed. Valparaíso: Edeval, 2015.

BLAUG, M. Economy theory in retrospect. $4^{a}$ edición. Londres: Cambridge University Press, 1985.

BUCHANAN, J. M.; TULLOCK, G. The calculus of consent. Indianapolis: Liberty Fund, 1990.

BUZAID, A. A influência de Liebman no direito processual civil brasileiro. Revista da Faculdade de Direito da Universidade de São Paulo, San Pablo, v. 72, n. 1, p. 131-152, 1977.

CALABRESI, S. G.; BERGHAUSEN, M. E.; ALBERTSON, S. The Rise and Fall of the Separation Powers. Northwestern University Law Review, Chicago, v. 106, n. 2, p. 527-549, 2012.

CHÁVEZ FICA, R.V. Participación pública en la evaluación de impacto ambiental y conflicto ambiental: un análisis desde el derecho internacional. Justicia Ambiental, Santiago, n. 7, p. 80-109, 2015.

CIFOLETTI, G. Mathematics and Rhetoric. Introduction. Early Science and Medicine, v. 11, n. 4, p. 369-389, 2006a.

CIFOLETTI, G. Valla to Viète: The Rhetorical Reform of Logic and Its Use in Early Modern Algebra. Early Science and Medicine, v. 11, n. 4, p. 390-423, 2006 b.

COASE, R. H. Law and Economics at Chicago. The Journal of Law and Economics, Chicago, v. 36, p. 239-254, 1993. 
COHEN, J. E. The regulatory state in the information age. Theoretical Inquiries in Law, v. 369, p. 369-414, 2016.

COOTER, R.; ULEN, T. Law and economics. Estados Unidos: Harper Collins, 1988.

COSTA CORDELLA, E.; MERINO FUENTES, P. La participación ciudadana en las declaraciones de impacto ambiental. Justicia Ambiental, Santiago, v. 3, p. 83-106, 2011.

CROLEY, S. P. Public interested regulation. Florida State University Law Review, Tallahassee, v. 28 , n. 7, p. 7-108, 2000-2001.

CROLEY, S. P. Regulation and public interests: the possibility of good regulatory goverment. Nueva Jersey: Princeton University Press, 2008.

DAHL, R. A. Who governs? Democracy and power in a American City. Londres:Yale University Press, 1961.

DAHL, R. A. La poliarquía: participación y oposición. Madrid: Tecnos, 1989.

DAWKINS, R. The selfish gene. 3era edición. ed. Oxford: Oxford University Press, 1989.

DE MORAES, O. J. Economia ambiental: instrumentos econômicos para o desenvolvimento sustentável. San Paulo: Centauro Editora, 2009.

DE MULDER, R.;VAN NOORTWIJK, K.; LIA, C.-K. Jurimetrics Please! European Journal of Law and Technology, Belfast, v. 1, n. 1, 2010. Disponible en: <http://ejlt.org/article/view/13/12>.

DEVLIN, A. Law and Economics. Irish Jurist, Dublin, v. XLV, p. 165-197, 2010.

DOWNS, A. An economic theory of democracy. Nueva York: Harper \& Row, 1957.

FARBER, D. A. Toward a New Legal Realism. University of Chicago Law Review, Chicago, v. 68, n. 1, p. 279-304, 2001.

FARO DE CASTRO, M. Análise jurídica da política económica. Revista da Procuradoria-Geral do Banco Central, Brasilia, v. 3, n. 1, p. 17-70, jun. 2009.

FERNÁNDEZ BITTERLICH, P. Manual de derecho ambiental chileno. 3. ed. Santiago: Thomson Reuters, 2013. 
FERRADA BÓRQUEZ, J. C. EL Estado Administrador de Chile: de unitario centralizado a descentralizado y desconcentrado. Revista de Derecho, Valdivia, v. 10, p. 115-123, 1999. Disponible en: <http:/ / revistas. uach.cl/html/revider/v10n1/body/art11.htm>.

FERRADA BÓRQUEZ, J. C.; BORDALÍ SALAMANCA, A.; CAZOR ALISTE, K. El recurso de protección como mecanismo de control jurisdiccional ordanirio de los actos administrativos: una respuesta inapropiada a un problema jurídico complejo. Revista de Derecho, Valdivia, v. 14, p. 67-81, 2002.

FRIEDMAN, M. The metodology of positive economics. In: FRIEDMAN, M. Essays in positive economics. Chicago: University of Chicago Press, 1966. p. 3-16, 30-43.

GRANZIERA, M. L. Direito ambiental. San Pablo: Atlas, 2009.

GREEN, D. P.; SHAPIRO, I. Pathologies of rational choice theory: a critique of applications in political science. Londres: Yale University Press, 1994.

GUEDES CRESPO, S. Eleito como deputado federal mais votado, Tiririca leva consigo mais de 3 candidatos. O Estado de S. Paulo, San Paulo, 3 out. 2010. Disponible en: <http:/ / politica.estadao. com.br/noticias/geral, eleito-como-deputado-federal-mais-votado-tiririca-leva-consigo-mais-de-3candidatos, 619725>.

HOOVER, K. D. Why does methodology matter for economics? The Economic Journal, Oxford, v. 105, n. 430, p. 715-734, maio 1995.

HOWLETT, M.; RAMESH, M.; PERL, A. Política pública: seus ciclos e subsistemas - uma abordagem integral. Río de Janeiro: Elsevier, 2013.

IMMERGUT, E. M. Institutional constraints on policy. In: GOODIN, R. E. The Oxford Handbooks of Political Science. Oxford: Oxford University Press, 2006. Cap. 27, p. 557-571.

INSTITUTO NACIONAL DE DERECHOS HUMANOS. Mapa de conflictos socioambientales en Chile. 2015. INDH. [S.l.], p. 262. 2016.

JAEGER ZABALA, F.; FEIJÓ SILVEIRA, F. Estatística aplicada ao direito. Direito e Liberdade, Natal, v. 16, n. 1, p. 87-103, 01-04 2014.

JEZE, G. Principios generales de derecho administrativo. Traducción de Julio N. San Millán Almagro. Buenos Aires: Depalma, v. 2.1, 1949. 
JORDAN, G. The Process of Government and The Governmental Process. Political Studies, p. 788 $801,2000$.

LEITE SAMPAIO, J.; WOLD, C.; NARDY, A. Princípios de Direito Ambiental na dimensão internacional e comparada. Belo Horizonte: Del Rey, 2003.

LENTINI, A. Istituzioni di diritto amministrativo. Milán: Società Editrice Libraria, v. 1, 1939.

LOEVINGER, L. Jurimetrics: the next step foward. Minnesota Law Review, Minneapolis, v. 33, n. 5, p. 455-493, abr. 1949.

MATTEI, L. Gênese e agenda do novo desenvolvimentismo brasileiro. Revista de Economia Política, San Paulo, v. 33, n. 1, p. 41-59, 01-03 2013.

MAYER, O. Derecho administrativo alemán. Traducción de Horacio H. Heredia y Ernesto Krotosckin. Buenos Aires: Depalma, v. 4, 1954.

MELO, A. M. Institutional Design, Normative Political Theory and Accountability. Revista Direito GV, Fundação Getulio Vargas, San Paulo, v. 195, n. especial, p. 195-206, 2005.

MOORE, M. 5 Reasons Why Trump Will Win. Michael Moore, 2016. Disponible en: <https:// michaelmoore.com/trumpwillwin/>. Aceso el 25 ago. 2017.

NAVIA, P. Chile: continuidad y cambio. Nueva Sociedad, 2006. Disponible en: <https://www. academia.edu/3127352/Chile_Continuidad_y_cambio>.

NEUMANN, M. The environmental law system of the Federal Republic of Germany. Annual Survey of International \& Comparative Law, p. 69-110, 1996. Disponible en: <http: / / digitalcommons. law.ggu.edu/cgi/viewcontent.cgi?article $=1021 \&$ context $=$ annlsurvey $>$.

NISKANEN, W. A. Bureucrats and politicians. The Journal of Law and Economics, v. 3, n. 18, p. 617-643, dez. 1975.

NORTH, C. D. Institutions. The Journal of Economic Perspectives, v. 5, n. 1, p. 97-112, 1991.

OLSON, M. The logic of collective action. Massachusetts: Harvard University Press, 1971.

OLSON, M. The rise and decline of nations: economic growth, stagflation, and social regidities. Nueva York: Yale University Press, 1982. 
OSTROM, E. Governing the commons: the evolutions of institutions for collective action. EE.UU.: Cambridge University Press, 1990.

PIERRY, P. El recurso de protección y lo contencioso administrativo. Revista de Derecho, Concepción, v. 165 , p. 153-173, 1977.

PIERSON, P. Increasing returns, path dependence, and the study of politics. The American Political Science Review, v. 94, n. 2, p. 251-267, 2000.

PISTOR, K. A legal theory of finance. Journal of Comparative Economics, v. 41, p. 315-330, 2013.

ROBBIN, L. An essay on the nature and significance of economic science. Londres: MacMillan \& Co., 1932.

ROSSI, J. Overcoming Parochialism: State Adminstrative Procedure and Institutional Design. Administrative Law Review, Washington, v. 53, n. 2, p. 551-573, 2001.

SCHWARTZ, B.; WADE, H. W. R. Legal control of government. Londres: Claredon Press, 1972.

SERVICIO DE EVALUACIÓN AMBIENTAL. Servicio de Evaluación Ambiental. Estudio de Impacto Ambiental Proyecto El Morro. 25/11/2008, 2017a. Disponible en: <http://www.sea.gob.cl/rca>. Acceso el 2 feb. 2017.

SERViCiO DE EVAluACiÓn AMBIEnTAL. Servicio de Evaluación Ambiental. Proyecto Hidroeléctrico Aysén. 14/08/2008, 2017b. Disponible en: <http://www.sea.gob.cl/rca>. Acceso el: 2 feb. 2017.

STIGLER, G. J. The theory of economic regulation. The Bell Journal of Economics and Management Science, v. 2, n. 1, p. 3-21, 1971.

THAGARD, P. R. The best explanation: criteria for Choice Theory. Journal of Philosophy, v. 75, n. 2, p. 76-92, fev. 1978.

VIDAL OLIVARES, Á.; BRANTT ZUMARÁN, M. G. Obligación, incumplimiento y responsabilidad del mandatario en el código civil chileno. Revista Chilena de Derecho, Santiago, v. 40, n. 2, p. 413-431, ago. 2013.

VILlALOBOS, J. C. Apoyar a Velasco desfiguraría a la centro derecha. Cosas, 13 out. 2017. Disponible en: <http://cosas.com/juan-diego-santa-cruz-apoyar-velasco-desfiguraria-la-centroderecha/>. 
WAGNER, W. E. Administrative law, filter failure, and information capture. Duke Law Journal, v. 59, n. 7, p. 1321-1432, abr. 2010.

\section{CómO CITAR ESTE ARTícuLO:}

ARANDA ORTEGA, Jorge. La falibilidad de la captura del Estado en la evaluación de impacto ambiental en Chile. Revista Direito GV, v. 15, n. 3, set./dez. 2019, e1932. doi: http://dx.doi.org/10.1590/ 2317-6172201932.
Jorge Aranda Ortega

Doctor en Derecho, Universidad de Brasilia. Profesor Asistente e Investigador, Centro de Derecho Ambiental, UNIVERSIDAD DE CHILE.

jarandaladerecho.uchile.cl j.aranda.olagmail.com 